\title{
Central composite design and optimization by multiresponse analysis of octacalcium phosphate synthesis*
}

\author{
J.-C. Heughebaert ${ }^{1}$, A. Lebugle ${ }^{1}$, F. Vu ${ }^{1}$ and R. Phan-Tan-Luu ${ }^{2}$
}

${ }^{I}$ Institut National Polytechnique de Toulouse, École Nationale Supérieure de Chimie, Laboratoire Interfaces et Matériaux, UPRESA CNRS $n^{\circ}$ 5071, 38, rue des Trente-Six Ponts, 31400 Toulouse, France

${ }^{2}$ Laboratoire de Méthodologie de la Recherche Expérimentale, Centre de Saint-Jérôme, Escadrille Normandie-Niemen, Université d'AixMarseille, 13397 Marseille Cedex 20, France

Synthesis of octacalcium phosphate (OCP) by hydrolysis of brushite was studied using a 3 block central composite design including 4 factors and 6 responses. Analysis of the responses allowed the definition of one set of experimental conditions in which OCP was obtained with the highest overall desirability (87.6\%).

everal routes of synthesis were proposed to prepare octacalcium phosphate (OCP) having the formula $\mathrm{Ca}_{8} \mathrm{H}_{2}\left(\mathrm{PO}_{4}\right)_{6} .5 \mathrm{H}_{2} \mathrm{O}$, and a triclinic structure $[1,2,3]$. Usually, it was obtained by slow hydrolysis of brushite $\mathrm{CaHPO}_{4} \cdot 2 \mathrm{H}_{2} \mathrm{O}$ (DCPD) carried out at $40{ }^{\circ} \mathrm{C}$ in buffered aqueous medium (sodium acetate $0.5 \mathrm{M}$ ). The solution was changed when the $\mathrm{pH}$ decreased and reached 6.1. This synthesis method was not as easy as it may seem because the hydrolysis reaction depends on several parameters $(\mathrm{pH}$, time, temperature, solid/solution ratio, stirring speed, specific surface area of brushite, etc). The mixture obtained was composed of DCPD and OCP, or of OCP and deficient apatite. Indeed it is well known that OCP becomes transformed at $\mathrm{pH}$ values higher than 5 , leading to a deficient hydroxyapatite of formula $\left[\mathrm{Ca}_{10-x}\left(\mathrm{PO}_{4}\right)_{6-x}\left(\mathrm{HPO}_{4}\right)_{x}(\mathrm{OH})_{2-x}, 0 \leq x \leq 2\right]$ with a $\mathrm{Ca} / \mathrm{P}$ atomic ratio lower than $1.67[2,3]$.

In order to avoid these difficulties, we performed a systematic study of DCPD hydrolysis transformation into OCP by considering the effect of 4 experimental parameters: $\mathrm{pH}$, maturation time, reaction temperature and ratio of brushite weight introduced in a constant volume of deionised water (400 mL). The stirring speed was $300 \mathrm{rpm}$. Brushite was prepared by double decomposition of ammonium phosphate and calcium nitrate. Its specific surface area was $3.4 \mathrm{~m}^{2} \cdot \mathrm{g}$. The $\mathrm{pH}$ was maintained constant by addition of ammonia dispensed by a microburette monitored with a pH-stat
(Fig. 1). Depending on the $\mathrm{pH}$ (more or less acid), the following reactions can take place:

$$
\begin{gathered}
8 \mathrm{CaHPO}_{4}, 2 \mathrm{H}_{2} \mathrm{O}+2 \mathrm{NH}_{4} \mathrm{OH} \rightarrow \mathrm{Ca}_{8} \mathrm{H}_{2}\left(\mathrm{PO}_{4}\right)_{6} .5 \mathrm{H}_{2} \mathrm{O}+ \\
2\left(\mathrm{NH}_{4}\right) \mathrm{H}_{2} \mathrm{PO}_{4}+13 \mathrm{H}_{2} \mathrm{O} \\
8 \mathrm{CaHPO}_{4}, 2 \mathrm{H}_{2} \mathrm{O}+4 \mathrm{NH}_{4} \mathrm{OH} \rightarrow \mathrm{Ca}_{8} \mathrm{H}_{2}\left(\mathrm{PO}_{4}\right)_{6} .5 \mathrm{H}_{2} \mathrm{O}+ \\
2\left(\mathrm{NH}_{4}\right)_{2} \mathrm{HPO}_{4}+15 \mathrm{H}_{2} \mathrm{O}
\end{gathered}
$$

At fixed times, samples were withdrawn by filtration, and dried at $60{ }^{\circ} \mathrm{C}$ in an oven. They were then examined by chemical analysis (determination of $\mathrm{Ca} / \mathrm{P}$ atomic ratio), by $\mathrm{X}$-ray diffraction, by FTIR and by Scanning Electron Microscopy. Their specific surface area was established by B.E.T.

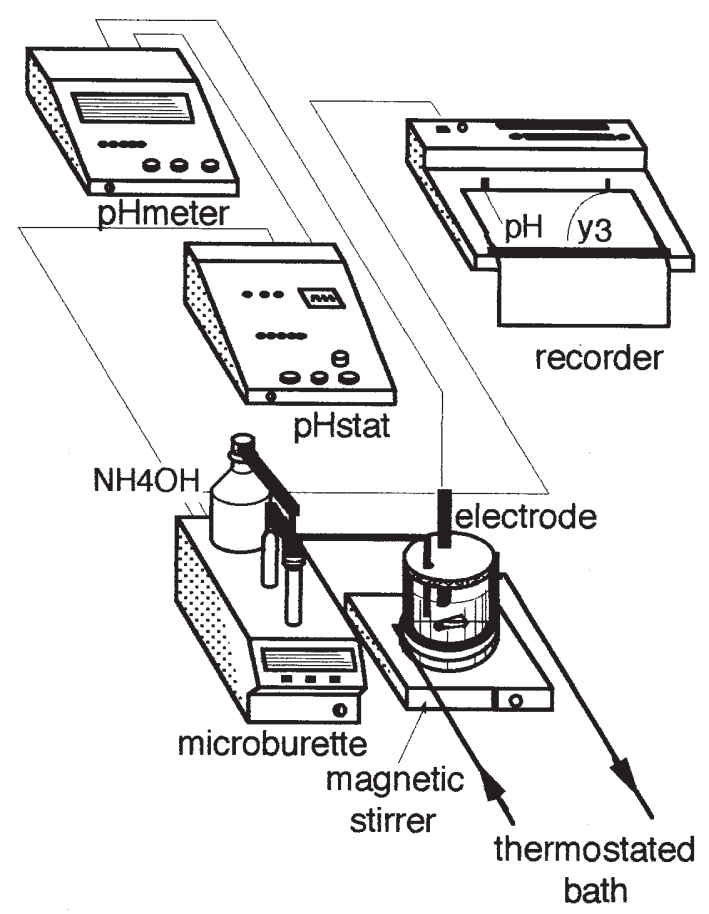

Figure 1. Experimental reactor.

* Tables I to $\mathrm{X}$ are available in electronic form at: www.edpsciences.org. 
This study was carried out using an orthogonally blocked central composite design [4], which was also rotatable. In this design, the factors are the experimental parameters considered above: $\mathrm{pH}$, time, temperature, and liquid-to-solid ratio. The values used in this design and the levels $X_{i}$ of the 4 factors are indicated in table I.

In order to limit the number of runs, each experiment was done in random in the 3 following blocks [4]: the first block with a fractional factorial design $2^{4-1}$ (with $I=-X_{1} X_{2} X_{3} X_{4}$ ) with 2 center points, the second block according to a factorial design $2^{4-1}$ (with $I=+X_{1} X_{2} X_{3} X_{4}$ ) with 2 center points, the third block according to axial design with the distance to center $\alpha$ equal to 2 , and with 2 center points. The values of the factors used in this design are reported in table II.

Responses $y_{u}$ included responses $y_{1}, y_{2}, y_{3}$ and $y_{5}$ defined below, and responses $y_{4}$ and $y_{6}$ computed from the previous ones $\left(y_{4}=y_{3} / x_{4}\right.$ and $\left.y_{6}=y_{5} / x_{4}\right)$ are:

- $y_{1}: \mathrm{Ca} / \mathrm{P}$ atomic ratio $(\mathrm{Ca} / \mathrm{P}$, no units $)$,

- $y_{2}$ : specific surface area (SS, in square meters per gram),

- $y_{3}$ : volume of ammonia $(6 \mathrm{M})$ added to maintain the $\mathrm{pH}$ constant $\left(\mathrm{V}_{\mathrm{NH} 4}\right.$, in $\left.\mathrm{mL}\right)$,

- $y_{4}$ : (ratio volume of ammonia $(6 \mathrm{M})$ to initial brushite weight $)^{*} 100 \equiv\left(\% y_{3} / x_{4}\right.$, in $\mathrm{mL}$ per gram $)$,

- $y_{5}$ : weight of solid after reaction (RM in gram),

$-y_{6}: \%$ ratio of solid weight after reaction to initial brushite weight $\equiv \%$ of $y_{5} / x_{4}$, (without units).

The six responses $y_{u}$ are not all independent of each other. From this fact it is necessary to calculate the $\mathbf{D}$ matrix (of dimension 30,6$)=\left\{y_{i u}-\overline{y_{u}}\right\}$ of individual means deviations [5] with column-centered. But as all the responses are not in the same unit system, it is necessary to treat $\mathbf{N}$ matrix (of dimensions 30,6) which is the normalized matrix. The symmetric normalized matrix $\mathbf{N}$ 'N (of dimension 6,6), without units, is reported table III.

The eigenvalues $\Lambda_{i}$ of $\mathbf{N}$ 'N in decreasing order, are:

$\Lambda_{1}=128.86 ; \Lambda_{2}=37.07 ; \Lambda_{3}=7.28 ; \Lambda_{4}=3.08 ; \Lambda_{5}=1.96 ;$ $\Lambda_{6}=1.77$

and the eigenvectors $z_{i}$ shown in table IV.

The first eigenvalue $\Lambda_{1}$ is about 70 times greater than the last two $\Lambda_{5}$ and $\Lambda_{6}$. It is clear that the possibility to estimate the responses in our model come from a great part of $z_{1}$, the eigenvector associated to $\Lambda_{1}$. Eigenvalues and eigenvectors analysis help in uncovering the linear relationships which exist among the observations $y_{u}$.

In experimental design, the equation of estimated responses $\hat{y}$ can be written:

$$
\hat{y}=b_{0}+\sum_{i=1}^{4} b_{i} X_{i}+\sum_{i=1}^{4} \sum_{j>i}^{4} b_{i j} X_{i} X_{j}+\sum_{i=1}^{4} b_{i i} X_{i}^{2}
$$

using SAS-JMP [6] and NEMROD [7] softwares, we found the values reported in table $\mathrm{V}$.

So, there are 15 coefficients to estimate. However, the classical equation (1) may be reduced to its canonical form (2) in which only 6 coefficients have to be estimated:

$$
\hat{y}=\hat{y}_{S}+\sum_{i=1}^{4} \lambda_{i} Z_{i}^{2}
$$

where $Z_{i}$ is a linear combination of $X_{i}$.

In equation (2), $\hat{y}_{S}$ is the optimum of $\hat{y}$ (maximum, minimum, minimax) and $\lambda_{i}$ is the eigenvalue of the determinant of symmetric matrix $\mathbf{B}=\left\{b_{i j}\right\}$, which comprises the interaction terms $\left(b_{i j}=b_{j i}\right)$ and the quadratic terms $\left(b_{i i}\right)$. The results $\left(\lambda_{i}\right)$ are given in table $\mathrm{V}$.

Moreover, the multilinear responses lead to the following correlation matrix and are reported in table VI. We verify at the same time, that the responses are not independent, but strongly correlated in most cases. From the correlation matrix, it is possible to calculate the eigenvalues (Lambda $\alpha$ ), in decreasing order and the eigenvectors $\left(u_{\alpha j}\right)$ in the same order (Tab. VII). The eigen structure table is useful for identifying the shape and orientation of the hyperellipsoids and results. The first eigenvalue is $\sim 3.5$ times the second value (4.4088/1.2437), and $~ 20$ times the third value (4.4088/0.2165). Moreover the proportion of lambda for axes 1 and 2 is $94 \%$ (Tab. VII). That means that the axes 1 and 2 are by far the two most important.

From this table it is possible to analyse the three principal components [8], $\operatorname{Axe}_{\alpha(j)}=u_{\alpha j} \sqrt{\text { Lambda } \alpha}$, where $\alpha$ is the eigenvalue, and $j$ the $j^{\text {th }}$ eigenvector (Tab. VIII). Axes 1 and 2 are the two principal components (Fig. 2). The responses $y_{u}$ are close to the correlation circle. That means that axes 1 and 2 are nearly the only ones to represent the effect on all the responses $y_{u}$. Moreover, the $\mathrm{Ca} / \mathrm{P}$ ratio is almost on axis 1 (0.980), and the \% of solid mass is correlated negatively to axis $1(-0.968)$, and therefore to $\mathrm{Ca} / \mathrm{P}$. Finally, the volume of $\mathrm{NH}_{4} \mathrm{OH}$, and the recovered mass are $60^{\circ}$ and $106^{\circ}$ from axis 1: that means that these two factors are practically independent of the $\mathrm{Ca} / \mathrm{P}$ ratio, and almost independent of each other. We will discuss this important point in a following paper.

It is possible from this component analysis (Fig. 2), to write the estimated responses $\hat{y}_{1}$ and $\hat{y}_{5}$. These responses are of particular interest because they explain the composition of the product and the recovered mass, where the numbers in parentheses are the standard errors of the coefficients, from which we obtain:

atomic ratio: $\mathrm{Ca} / \mathrm{P}$ :

$$
\begin{aligned}
\hat{y}_{1(5 \%)}= & 1.342(0.008)+0.069(0.004) X_{1}+0.010(0.004) X_{2} \\
& +0.044(0.004) X_{3}-0.020(0.004) X_{4} \\
& -0.014(0.005) X_{1} X_{2}-0.032(0.005) X_{1} X_{3} \\
& +0.022(0.005) X_{1} X_{4}-0.026(0.004) X_{1}^{2} \\
& -0.028(0.004) X_{3}^{2}
\end{aligned}
$$




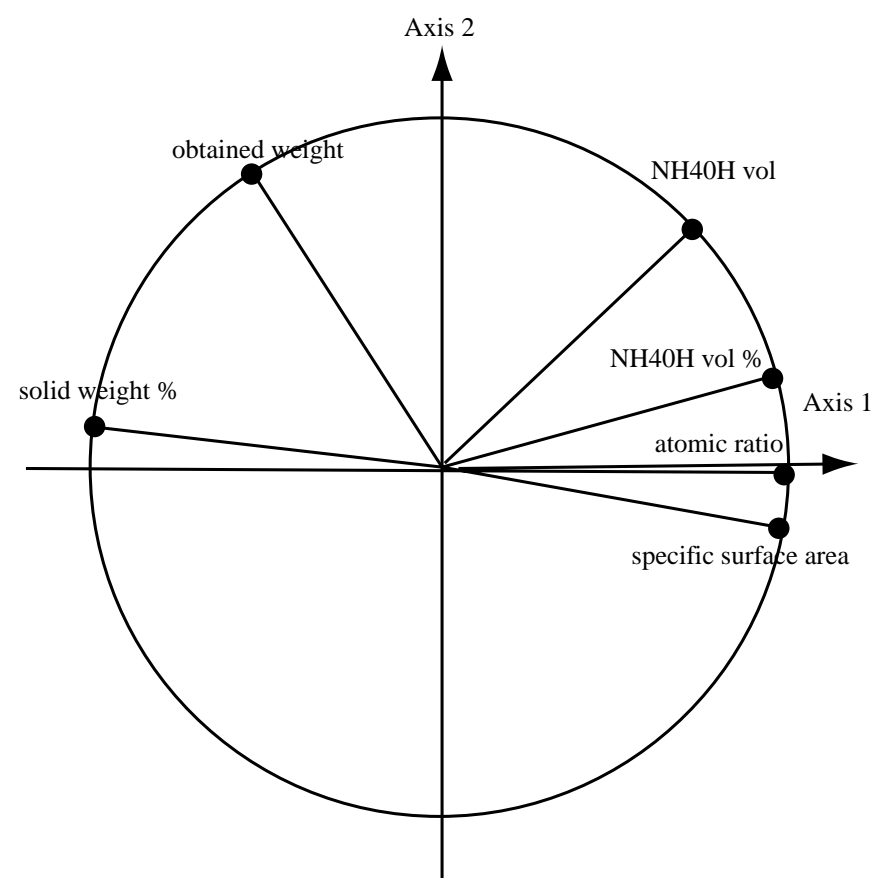

Figure 2. Principal components of the 6 responses according to Axis 1 and Axis 2.
RM (gram):

$$
\begin{aligned}
\hat{y}_{5(5 \%)}= & 4,50(0.07)-0.39(0.03) X_{1}-0.22(0.03) X_{3} \\
& +1.59(0.03) X_{4}+0.17(0.04) X_{1} X_{3}-0.23(0.04) \\
& X_{1} X_{4}-0.14(0.04) X_{3} X_{4}+0.18(0.03) X_{1}^{2} \\
& +0.13(0.03) X_{3}^{2}
\end{aligned}
$$

The analysis of these responses shows that a set of experimental conditions exist (without taking the blocks into account) which easily leads to a product composed of only triclinic OCP. The set (in ordinary units) for symmetrical linear desirability $d_{u}(\%)$ as a function of $y_{u}$ is [9] :

$$
\begin{aligned}
& d_{1}=0 \text { for } y_{1}<1.313 \text { and }>1.353, d_{1}=100 \text { for } \begin{array}{c}
y_{1}=1.333 \\
\text { (two-sided) }
\end{array} \\
& d_{2}=0 \text { for } y_{2}<32 \text { and }>42, d_{2}=100 \text { for } y_{2}=37, \\
& \text { (two-sided) }
\end{aligned}
$$

The set corresponds to synthesis for which the overall desirability is $87.6 \%$. In tables IX and X we report the coordinates of maximum of overall desirability. Extrapolation to
$X 2=0.586 \times 4=1.576$

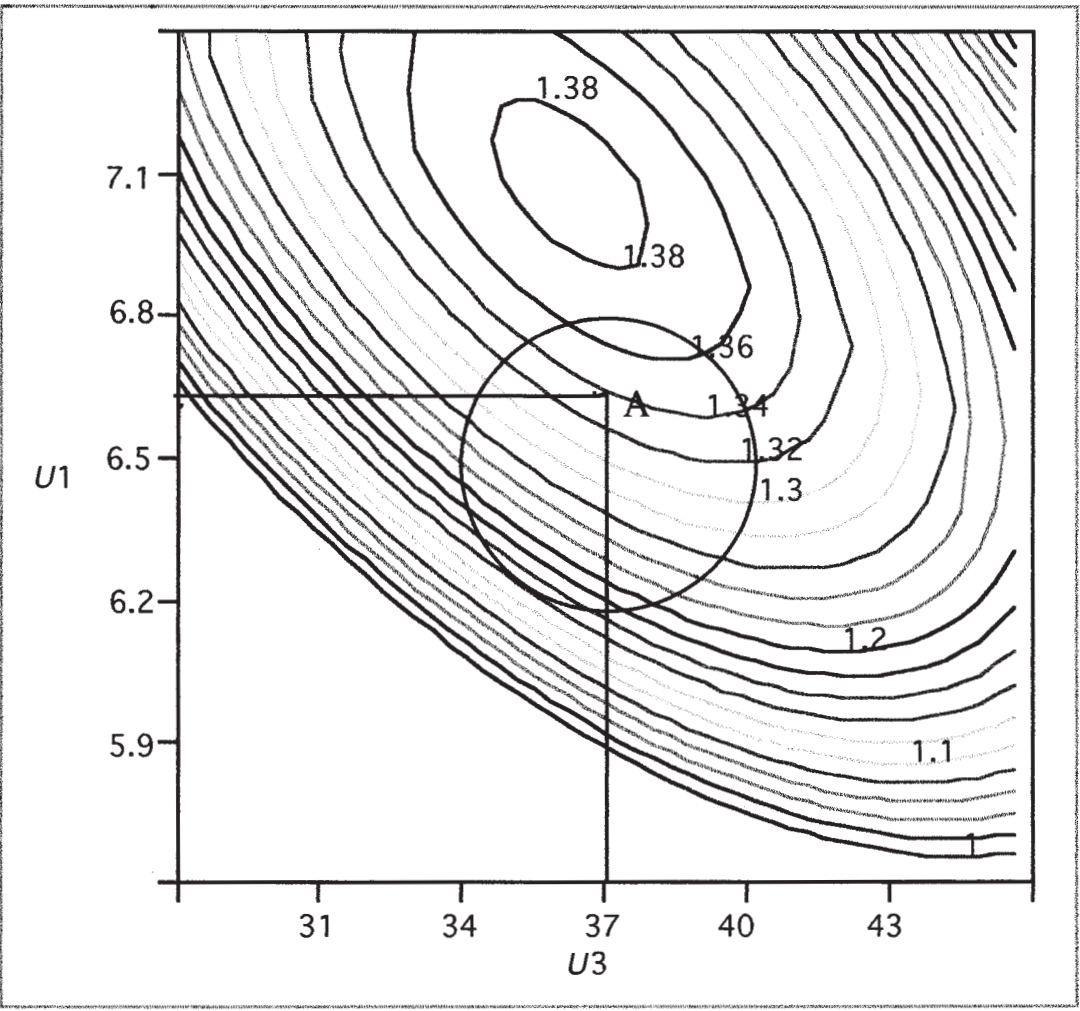

Figure 3. Level contours for $y_{1}=\mathrm{Ca} / \mathrm{P}$, with $U_{2}=18$ hours and $U_{4}=24.4 \mathrm{~g} \cdot \mathrm{L}^{-1}$. 
the industrial scale should however be checked. The relative level contours $\hat{y}_{1}, \mathrm{Ca} / \mathrm{P}$ ratio, where established with $X_{2}=0,586$ (Fig. 3). In this figure, we show the A point $\left(X_{1}=0.403 ; X_{2}=0.586 ; X_{3}=0.027 ; X_{4}=1.536\right)$, where the overall function desirability is equal to $87.6 \%$ $(\mathrm{Ca} / \mathrm{P}=1.335)$.

The set does not correspond to the laboratory synthesis. Factor $U_{2}$ must be $\leq \approx 10$ hours or $\geq \approx 15$ hours (Tab. I), so that the end of the synthesis does not occur during the night. So, factor $U_{4}$ (brushite mass/water volume) must be as high as possible. This depends on the experimenter.

Before applying these experimental conditions, the validity of the empirical mathematical design obtained must be checked by carrying out three complementary runs. We calculated the theoretical responses from the empirical model, and compared them to experimental responses. If we take experimental incertainty into consideration we can also say that the model is well supported.

The physical-chemical discussion of this center-composite design will be examined in a forthcoming paper.

\section{References}

1. Brown, W. E.; Lehr, J. R.; Smith, J. P.; Frazier, A. W. J. Am. Chem. Soc. 1957, 79, 5318-5319.

2. LeGeros, R. Z. Calcif. Tissue Int. 1985, 37, 194-197.

3. de Rooij, J. F.; Heughebaert, J.-C.; Nancollas, G. H.; J. of Colloid and Interface Science 1984, 100, 350-358.

4. Box, G. E. P.; Draper, N. R. Empirical Model-Building and Response Surfaces; New-York: Wiley \& Sons, 1987, p 514 (table 15.3) and p 527 (ex: 15.7).

5. Box, G. E. P.; Hunter, W. G.; MacGregor, J. F.; Erjavec, J. Technometrics 1973, 15(1), 33-51.

6. SAS Institut, JMP (version 3.2), 1997, Domaine de Grégy, BP 5, 77166 Grégy-sur-Yerres, France.

7. NEMROD Software, 1999, Mathieu, D.; Nony, J.; Phan-TanLuu R. LPRAI, B.P.7, 13311 Marseille, Cedex 14, France.

8. Rencher, A. C; Method of Multivariate Analysis; New-York: Wiley \& Sons, 1995, pp 415-444.

9. Derringer, G. C.; Suich, J. J. Quality Technology 1980, 12, 214219. 